Bettina Schmitz, Barbara Tettenborn, Donald L. Schomer (eds.)

\section{The Paroxysmal Disorders}

Cambridge University Press, Cambridge, 2010

226 pp.; GBP 60.00/USD 99.00

ISBN 978-0-521-89529-5

This book represents an English translation of a German text published in 2005, which according to the editor has been extensively reviewed and updated. It reflects a very interesting approach in clinical neurology, focusing on conditions occurring paroxysmally as their principal characteristic.

As opposed to the German version, there is no accompanying introductory word, but the first chapter, dealing with the history taking technique, represents a useful and logical start. The book contains 15 other chapters, each dealing with a more or less specific group of symptoms. The description of pediatric conditions is followed by sections on syncope, 'sudden falls' (basically dealing with epilepsy), headaches, vertigo and visual disturbances. Then, a chapter on 'paroxysmal paresis' (including stroke) precedes those on dyskinesias and other movement disorders, myoclonus, memory loss, psychogenic non-epileptic seizures (PNES), anxiety, vegetative seizures, and, finally, ataxias.

As a whole, the covered subjects are indeed very broad and encompass well what one may encounter in clinical practice. One problem inherent to works written by many authors is redundancy, which here is found for example for PNES (despite a dedicated chapter), cataplexy (several relatively short descriptions but no dedicated section), or drop attacks. In addition, despite the 'updating' intents, the texts appear at least in part relatively dated. For instance, there is no mention throughout the book about the link between paroxysmal exercise-induced dystonia, glucose transporter (GLUT1) deficiency, and epilepsy (which is known at least since 2008), and the therapeutic role of ketogenic diet. The section on epilepsy treatment does not mention medications marketed since 2006, but reports compounds that are nearly almost forgotten (as tiagabine). Furthermore, one would have expected more emphasis on conditions such as vestibular neuritis, epileptic amnesia, semiology of visual illusions/hallucinations (e.g. the role of color in the differential diagnosis between epileptic and migraine auras, or the superposition on the background for peduncular hallucinosis) and of paresis (e.g. no detailed description of the Hoover sign is found), or epilepsy-induced syncope, which may at times challenge the emergency physician/neurologist. Despite these drawbacks, several book parts are very well written and useful for the clinician, like the headache, the ENT (vertigo), sections of the ophtalmological, and the PNES chapters, while other encompass some details (e.g. epilepsy treatment, stroke diagnosis and treatment) that may go beyond the intent of the editors of this work.

In conclusion, despite finding much interesting information, the reader may welcome a truly updated edition of this book, where a general diagnostic overview of paroxysmal conditions (e.g. as a table or flow chart) could also contribute to a more homogeneous and synthetic result, and to an additional usefulness for the clinician.

\section{KARGER}

Fax +41613061234 E-Mail karger@karger.ch www.karger.com
(C) 2011 S. Karger AG, Base

0014-3022/11/0666-0350\$38.00/0

Accessible online at

www.karger.com/ene 